\title{
BEYOND TRAINING MINIMUMS - A NEW CONCEPT OF THE UAV OPERATOR TRAINING PROGRAM
}

\author{
Róbert SZABOLCSI \\ Óbuda University, Budapest, Hungary \\ szabolcsi.robert@bgk.uni-obuda.hu
}

\begin{abstract}
The UAV pilot/operator training is a crucial part being evaluated during certification of the unmanned aircraft systems (UAS). There are many milestones behind, many new initiatives are launched. However, many initiatives originated to the type of the crew training and certification originated to that of the minimum levels derived by regulations. There are two main approaches when establish a training organization. First is, the so-called approach of minimums (AoM) delivered to the operators. Second is originated to that of the set of skills (SoS) necessary to hold by operators to safe operation of the UAV. The author will examine two standpoints evaluating their privileges and bottlenecks, or, if there is any, the threat. New idea will be formulated by the author to combine advantages of those two approaches providing a new set of criteria for training system beyond present minimums.
\end{abstract}

\section{Keywords: UAS, UAS crew, UAS operator, operator training, crew certification.}

\section{Introduction}

Present days there are many ideas and initiatives about UAV designated operator training. Common feature here is that those available both military and civilian guidelines are defining training minimums and there are no upper limits in any means of it.

The training itself means to train UAV operators being educated in secondary grammar schools, in vocational training or in higher education institutions. The basic idea of the training is to train UAV operators able to handle UAVs safely both in flight and in ground operations.

In-spite of the existing guidelines being military or civil many countries made their reservations allowing taking into consideration experiences gained from operating UAVs in national airspaces under supervision of the national authorities.

As your paper is written for publication in the Conference Proceedings, it must address the interests of readers with diverse specialties and backgrounds as well as with the author's peers. Your manuscript must provide the details of the work to readers. It should be divided into sections, each with a heading, so that a reader can follow the logical development of the work.

\section{Related works}

The UAV airworthiness certification is analysed in deep details in reference works of the author in $[4,5,6,7]$. These papers are dealing only with many possible measures of compliance of the UAVs in their technical qualities and dynamic performances proposed by the author. Secondly, measure of compliance can be determined with that of pre-defined ones available in standards, guidelines, and handbooks.

Of course, to fly UAV safely it is 
necessary to own an educated and welltrained team being responsible for the flight safety, in general. There is a long lasting argue whether UAV operator is a pilot with its means, i.e. with rights and responsibilities. The military regulation goes far ahead to that of the civilian one, so this paper will analyse thoroughly two basic guidelines and regulations, which are the NATO STANAG 4670 [1] and The Joint Minimum Training Standards of the Joint Staff [3]. As a rule any NATO standard can serve as national rule if it is ratified by lawmakers. Due to sensitivity of the problem of the UAV operators' training still many NATO-member countries are in debt with ratification of the basic NATO document titled STANAG 4670/ATP-3.3.7 [2]. In close to that of STANAG 4670/ATP-3.3.7 principles goes The Joint Minimum Training Standards of the Joint Staff. These two basic documents derive guidelines for the principles of the training systems, and derive the syllabus in general. What is important, the basic norms are defined for the minimum levels of the skills of the operators, and, there are no formal upper limits for the syllabi of the training systems.

The civil UAV operators must be registered since January 2016, and minimum requirements for the operators are defined in [8]. The famous and well-known JAR-documents were transferred to that of the EASA PART documentation system, i.e. guideline and requirements for the aircraft maintenance staff of the conventional manned aircraft was shifted to that of EASA PART 66 [9]. The author had made first steps in the field of analysis syllabi in UAV operator training systems and published first paper in [10].

\section{The NATO STANAG 4670/ATP-3.3.7 Training Guidance}

The NATO STANAG 4670/ATP-

3.3.7 training guidance based upon three documents as follows below:
1) Chairman, CJCSI 3255.1, Joint Unmanned Aircraft Systems minimum training standards, originally dated 17 July 2009, Change 1, dated 31 October 2011, current version as of 4 September 2012;

2) AAP-03, Edition J, Version 1, dated November 2011;

January 2002.

3) AAP32)A), Change3, dated

The basic idea of the STANAG 4670 regulation is to segment four levels of basic UAS qualifications (BUQ). The trend here is when it is feasible and applicable the knowledge, skills and abilities (KSA) requirements bring closer to that of International Civil Aviation Organization (ICAO) requirements defined for manned aircraft of the civil aviation.

The first and basic document of NATO STANAG 4670 PFP(NNAGJCGUAV)D(2006)001-Rev2 was issued with request of ratification 13 September 2006, till 1 December 2006. There are many years had flown by, and still, a UAV designated operator training is a matter of argue between many organizations. The latter version of this regulation is called as NATO STANDARD ATP-3.3.7 (Edition B, Version 1) from 22 April 2014.

The ATP-3.3.7 standard has some records of specific reservations, including those that were recorded at time of the promulgation, and are as follows below:

1) Belgium

a. will continue to deliver own training syllabi;

b. will implement elements of BUQ Levels III and IV.

2) Canada

a. will not use term UAS;

b. the UAV classification of CDN is not consistent with scheme used by NATO;

c. will implement STANAG 4670 directed to training for the equivalent Canadian classification of the UAS.

3) Estonia: will use in dependence of UAS/UAV capabilities.

4) France

a. will not apply to class I drones; 
b. French Navy will apply as it receives the training equipment needed for the implementation;

c. French Army will not apply because it departs too much from its practices and equipment.

5) Great Britain

a. reservation due to metrics;

b. reservation to special regimes i.e. Stall Recovery, Dead Reckoning Navigation, Precision Radar Approaches;

c. reservation due to classification of the UAVs.

6) Italy: will recognize Basic UAS Qualifications in accordance with this document.

7) The Nederland

a. will mutually recognize UAS operators' training;

b. recognition and accreditation of qualifications issued by foreign authorities will be done by NLD Military Aviation Authority (MAA NLD);

c. possible fly under Visual Meteorologic Conditions (VMC).

8) USA

a. UAS bases its training on CJCSI 3255.01 document [3];

b. some subject knowledge requires higher standards than existing requirements of the USA.

From the list of reservations given above easy to understand that still there are many differences between UAV manufacturers and UAV users, and sometimes it is cannot be bridged, the only possibility is to keep reservations in the given fields differing much.

There are many initiatives to classify UAVs and UASs leading to the diversity of available classification [8]. To understand levels of BUQ [2] gives detailed classification of the UAS (Figure 1).

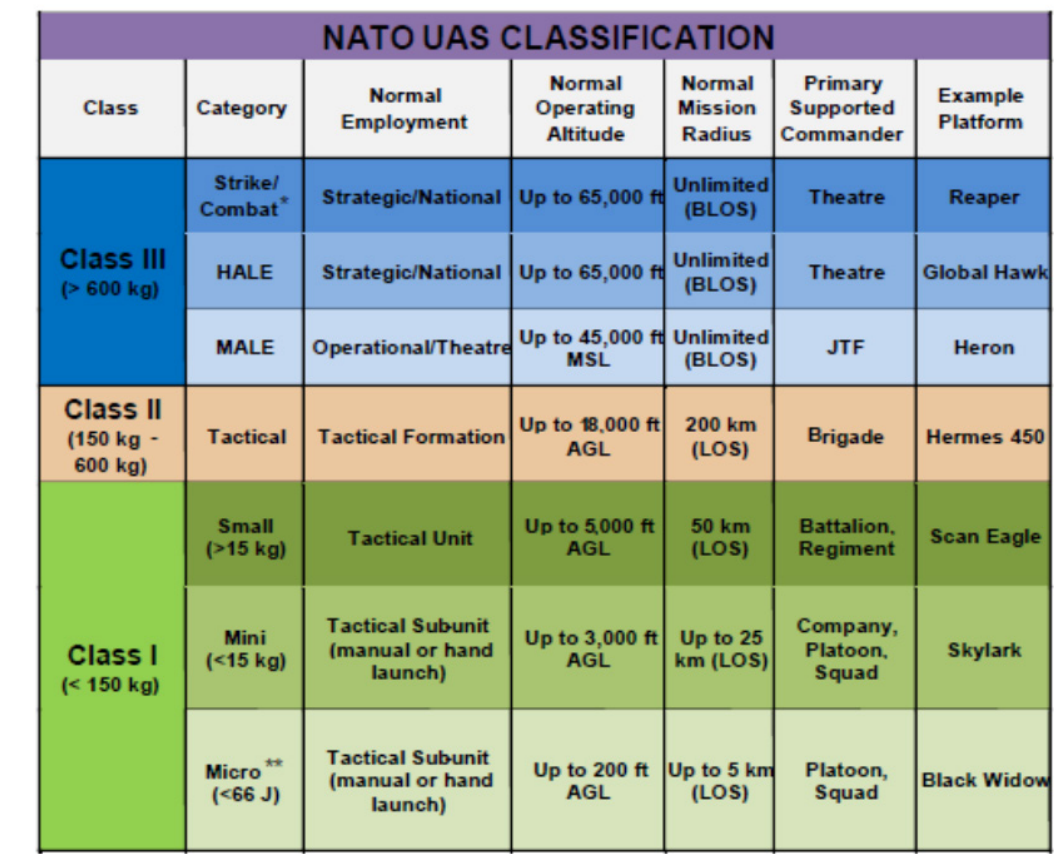

*Note: In the event the UAS is armed, the operator should comply with the applicable Joint Mission Qualifications in ATP-3.3.7 (STANAG 4670) and the system will need to comply with applicable air worthiness standards, regulations, policy, treaty, and legal considerations.

*Note: UAS that have a maximum energy state less than 66 Joules are not likely to cause significant damage to life or property, and do not need to be classified or regulated for airworthiness, training, etc. purposes unless they have the ability to handle hazardous payloads (explosive, toxins, chemical/ biological agents, etc.).

Figure 1: NATO UAS Classification [1, 2].

The ATP-3.3.7 using UAV MTOW data defines three UAV classes, which are important whilst to derive BUQ for four levels leaning on KSA-requirements. 
In $[1,2,3]$ a rating scale for UAS operators' skills was established to make difference between BUQ levels of the operators. Appropriate and certified BUQ levels provide strong foundation for the UAS operations both in military and in civil applications. The Basic UAS Qualification includes basic understanding of the weather, aerodynamics, human factors, operational risk management, and finally, flight regulations for the type of the airspace in which the UAS operates.

Before to start with BUQ Qualification levels' definitions it is important to understand and be familiarized with the airspace classification (Figure 2.)

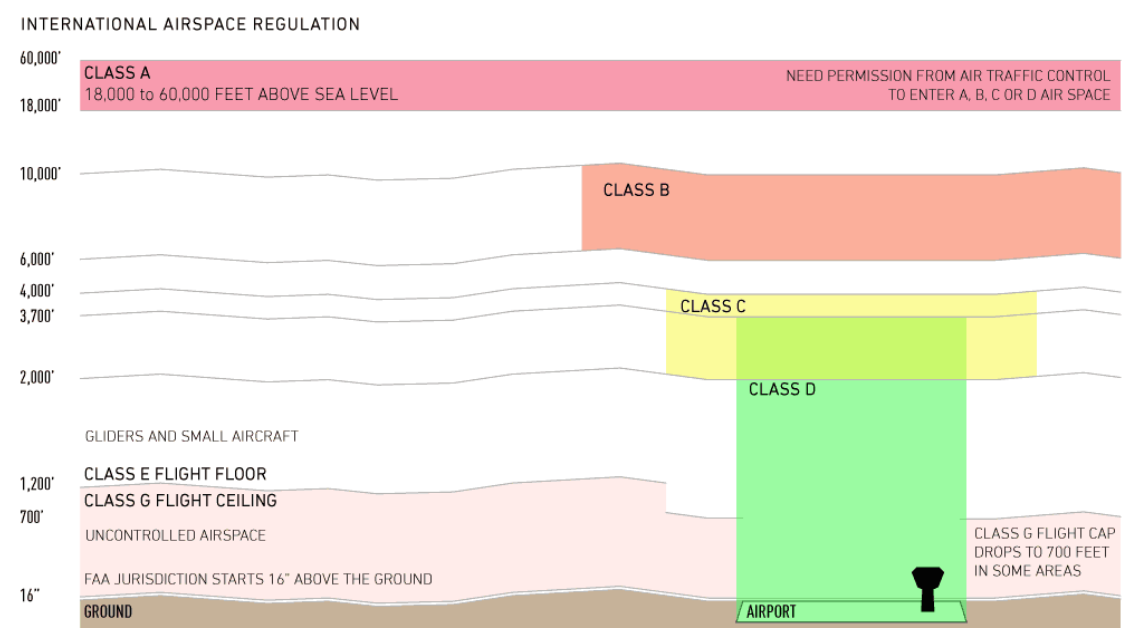

Figure 2 International Airspace Classification (Accessed at: www.google.com)

References [1, 2, 3] define following four BUQ levels as they defined below:

1) BUQ Level I: knowledge and skills required to operate under Visual Flight Rules (VFR) in ICAO Classes E, F, and $\mathrm{G}$, and Restricted/Combat airspace below $3000 \mathrm{ft}$ above ground level (AGL). NATO Class I, Micro and Mini UAS operators are to be trained to BUQ Level I.

2) BUQ Level II: knowledge and skills required to operate under VFR in ICAO Class D, E, F and G, and Restricted/Combat airspace below $5000 \mathrm{ft}$ AGL. NATO Class I, Small UAS operators must be trained to BUQ Level II.

3) BUQ Level III: knowledge and skills required to operate under VFR in all ICAO airspace except Class A below $18.000 \mathrm{ft}$ AGL or Flight Level (FL) 180. NATO Class II, Tactical UAS operators must be trained to BUQ Level III.

4) BUQ Level IV: knowledge and skills required to operate under VFR and Instrument Flight Rules (IFR) in all airspace. NATO Class III UAS, MALE/HALE and Strike/Combat UAS operators must be trained to BUQ Level IV.

The BUQ levels given above are cumulative ones. Therefore, to meet higher requirements, operators must meet all the requirements of the lower levels as well.

The general aeronautical knowledge content is defined by following areas:

1) Airspace structure and operating requirements; ATC procedures and rules of the air; Aerodynamics; Aircraft systems; Performance; Navigation; Meteorology; Communication procedures (Aeronautical English, ICAO Level 4); Mission preparation.

The basic guideline followed by rulemakers is that the achieved level of competence of the UAS operators must be maintained, its currency and proficiency must be adequate to that existing national minimum standards and requirements. The principle of expiration is followed: all operators must be subjected to periodic 
theoretical, practical and medical examination of the designated military examiners [1, 2, 3].

The basic aeronautical module is not explained yet, and its content belongs to those training organizations leading theoretical and practical training syllabi in UAS operator training.

The UAS operator training programs target to train UAV operators having pre-defined skills are divided into three main areas as follows:

1) Subject knowledge;

2) Task knowledge;

3) Task performance.

In these categories subcategories are defined with attributes to measure compliance to the given level of skills and knowledges of the UAS operators $[1,2$, 3].

\section{The USA DoT FAA Civil Regulations}

Besides military training syllabi of UAS designated operators, it is worth to mention the civil regulations. Of course, the national training programs may differ, but the FAA regulations are in the focus of attention of training organizations and experts not depending of its feature.

In 2015 a set of new norms were issued and published by FAA, which deals with UAS operators training and operators' responsibility, too. The UAV being flown is supposed to have wet weight less than $25 \mathrm{kgs}(55 \mathrm{lbs})$, with no lower weight limits. These basic principles defined by FAA are as follows [8]:

1) Pilots of small UAV would be considered for "operator" instead of "pilot" widely applied and used;

2) UAV operators must be at least 17 years old;

3) UAV operators would be required to:

a. pass an initial aeronautical knowledge test at an FAA-approved knowledge test center; b. be vetted by the Transportation Security Administration;

c. obtain an unmanned aircraft operator certificate with a small UAS rating (like existing pilot airman certificates, never expires);

d. pass a recurrent aeronautical knowledge test every 24 months;

e. make available to the FAA, upon request, the small UAS for inspection or testing, and any associated documents/records required to be kept under the proposed rule;

f. report an accident to the FAA within 10 days of any operation that results in injury or property damage;

g. conduct a preflight inspection, to include specific aircraft and control station systems checks, to ensure the small UAS is safe for operation.

It is easy to point out that there are many common points between military and civilian standpoints. As for the military training organizations, for the civil approved training organizations there is no strict regulations about aeronautical knowledge, and secondly, how it will be examined after 24 months.

\section{The EASA PART 66 Licence Guidance}

The EASA PART 66 regulation is a basic document dealing certifying maintenance staff of the manned aircraft. Due to lack of precize definition in STANAG 4670 of the aeronautical knowledges in the fields of $3,4,5,6$, and 9 defined in Chapter 3, it is worth to refer to that source of PART 66 applied very successfully during many decades in civil aviation showing its applicability.

Part 66 includes 17 modules as follows: Mathematics, Physics, Electrical fundamentals, Electronic fundamentals, Digital techniques, Materials and hardware, Maintenance practices, Basic aerodynamics, Human factors, Aviation legislation, Aeroplane aerodynamics, structures and systems (both jet and 
pistone engines), Helicopter aerodynamics, systems and structures, Aircraft aerodynamics, systems and structures, Propulsion, Gas turbine engines, Piston engine, Propeller.

Going into deep details and compare aeronautical knowledges, skills, and performances required by both 4670 and PART 66 regulations, it can be stated that:

a. PART 66 covers all aeronautical knowledges modules of covering Modules 3, 4, 5, 6, and 9 of STANAG 4670 regulation. It means that those organizations aproved by national authorities as training organization can issue certificate about given modules being evaluated by them. The missing modules must be identified and additional training is needed to acomplish basic aeronautical theoretial training defined by $[1,2,3]$.

b. PART 66 includes additional theoretical knowledges and skills in mathematics, physics, electronics, and digital techniques over those basic skills defined by $[1,2,3]$. There is a question remaining whether these basic knowledges and skills are necessary for the UAV operators, or there is no need for such knowledges. It is easy to agree that those modules of PART 66 not involved into STANAG 4670 mean some overload onto UAS operators, however the academic hours covering these modules are few in relationship to basic modules.

c. The PART 66 modules are covering those modules of STANAG 4670 of 3, 4, 5, 6, and 9 defined in Chapter 3, and this regulation can be considered adequate for the given part of the designated UAS operator, supplemented with those of missing chapters of 4670 document.

\section{Conclusions}

This paper deals with basic training programs of the UAS operators, involving only the aeronautical knowledges and skills required. It was stated that STANAG 4670 defining aeronautical skills in many fields, can be partly substituted by existing EASA PART 66 regulations. The knowledges and skills gained in civil sector can be accredited and received by the Military, with additional knowledges and skills.

\section{References}

[1]NATO STANAG 4670 (Edition 1) Recommended Guidance for the Training of Designated Unmanned Aerial Vehicle Operator (DUO), NATO Standardization Agency, 2006. http://everyspec.com/ (Accessed 24 Feb 2016).

[2]NATO STANAG 4670 - ATP-3.3.7, (Edition 3) Guidance for the Training of Unmanned Aircraft Systems (UAS) Operators, NATO Standardization Agency, 2014. http://everyspec.com/ (Accessed 24 Feb 2016).

[3]Joint Unmanned Aircraft Systems Minimum Training Standards, Joint Staff, Washington, D.C., 20318, 2012. http://www.dtic.mil/cjcs directives/sitemap.htm (Accessed 24 Feb 2016).

[4]R. Szabolcsi, A New Concept of the Basic Terms and Definitions for Measuring the UAV and UAS Systems Compliance with Airworthiness Criteria. Bolyai Szemle, ISSN 14161443, XXIII(1), pp(5-18), 2014.

[5]R. Szabolcsi, A New Concept of the Unmanned Aerial Vehicles Flying and Handling Qualities. Bolyai Szemle, ISSN 1416-1443, XXIII(1), pp(19-26), 2014.

[6]R. Szabolcsi, A New Approach of Certification of the Airworthiness of the UAV Automatic Flight Control System. Revista Academiei Fortelor Terestre/Land Forces Academy Review, ISSN 2247-840x, eISSN 1582-6384, 4/2014:(76), pp(423-431), 2014.

[7]R. Szabolcsi, Lateral/Directional Flying Qualities Applied in UAV Airworthiness Certification Process. Revista Academiei Fortelor Terestre/Land Forces Academy 
Review, ISSN 2247-840x, eISSN 1582-6384, 3/2014:(75), pp(336-346), 2014.

[8]USA DoT FAA, 14 CFR Parts 21, 43, 45, 47, 61, 91, 101, 107, and 183. Docket No.: FAA2015-0150; Notice No. 15-01, 2015.

[9]EASA PART 66 (JAR 66) Licence Guide (Accessed at http://aircraft-licence.com/Part66Syllabus.html).

[10]R. Szabolcsi, UAV Operator Training - Beyond Minimum Standards, The $18^{\text {th }}$ International Conference "Scientific Research and Education in the Air Force" AFASES 2016, Brasov, Romania (under evaluation and review). 